\title{
Myeloid-Derived Suppressor Cells in Inflammatory Bowel Disease
}

\author{
Yeon-Jeong Kim ${ }^{1}$, Sun-Young Chang ${ }^{2}$, Hyun-Jeong Ko ${ }^{3}$ \\ College of Pharmacy, Inje University', Gimhae, Ajou University', Suwon, and Kangwon National University ${ }^{3}$, Chuncheon, Korea
}

Immature myeloid cells, also known as myeloid-derived suppressor cells (MDSCs), include neutrophilic and monocytic myeloid cells, and are found in inflammatory loci and secondary lymphoid organs in mice with intestinal inflammation, inflammatory bowel disease (IBD) patients, and tumor tissues. However, the roles of MDSCs in IBD are not yet well understood, and there are controversies regarding their immunosuppressive functions in IBD. In addition, recent studies have suggested that endoplasmic reticulum (ER) stress in intestinal epithelial cells, especially in Paneth cells, is closely associated with the induction of IBD. However, the ER stress in MDSCs accumulated in the inflamed tissues of IBD patients is not yet fully understood. In the current review, we discuss the presence of accumulated MDSCs in the intestines of IBD patients, and further speculate on their physiological roles in the inflammatory condition with interleukin 17-producing cells, including Th17 cells. In particular, we will discuss the divergent functions of MDSCs in ER stressed intestinal environments, including their pro-inflammatory or immunosuppressive roles, based on the consideration of unfolded protein responses initiated in intestinal epithelial cells by ER stress. (Intest Res 2015;13:105-111)

Key Words: Inflammatory bowel diseases; Myeloid-derived suppressor cell; Endoplasmic reticulum stress; Intestines; Interleukin-17

\section{INTRODUCTION}

Inflammatory bowel disease (IBD) is a chronic inflammatory condition in the small and large bowel, and includes two major clinical forms, Crohn's disease (CD) and ulcerative colitis (UC). ${ }^{1}$ Although the exact causes of IBD are largely unknown, early studies aimed at identifying the genetic factors associated with human IBD revealed nucleotide-binding oligomerization domain-containing protein 2 (NOD2) as a CD-susceptibility gene. ${ }^{2}$ Ever since NOD2 was introduced,

Received January 16, 2015. Revised January 20, 2015.

Accepted January 21, 2015.

Correspondence to Hyun-Jeong Ko, Laboratory of Microbiology and

Immunology, College of Pharmacy, Kangwon National University, 1

Gangwondaehak-gil, Chuncheon 200-701, Korea. Tel: +82-33-250-6923,

Fax:+82-33-255-7865, E-mail: hjko@ kangwon.ac.kr

Financial support: This research was supported by Basic Science Research Program through the National Research Foundation of Korea (NRF) funded by the Ministry of Science, ICT and future Planning (NRF2014R1A2A2A01002576). Conflict of interest: None. many researchers have tried to find other genetic risk factors for IBD. Based on the efforts of many researchers, a considerable number of genetic risk factors, including solute carrier family 22, member 4 (SLC22A4), SLC22A5, prostaglandin E receptor 4 (PTGER4), interleukin 23 receptor (IL23R), autophagy related 16-like 1 (ATG16L1), immunity-related GTPase family M (IRGM), discs, large homolog 5 (DLG5), and X-box binding protein 1 (XBP1) have been found to be associated with the development of IBD in addition to NOD2. ${ }^{3-5}$ Among them, the genetic association of XBP1 polymorphisms with IBD was suggested by the presence of hypomorphic single-nucleotide polymorphisms in the XBP1 gene in IBD patients, and unabated endoplasmic reticulum (ER) stress was associated with the induction of intestinal inflammation shown in IBD patients. ${ }^{4}$

Interestingly, several genetic risk factors of IBD were found to be involved in the maturation and function of Paneth cells. ${ }^{6,7}$ Paneth cells are specialized epithelial cells that reside in the crypts of the small intestine, and produce antimicro-

๑ Copyright 2015. Korean Association for the Study of Intestinal Diseases. All rights reserved.

This is an Open Access article distributed under the terms of the Creative Commons Attribution Non-Commercial License (http://creativecommons.org/licenses/by-nc/3.0)

which permits unrestricted non-commercial use, distribution, and reproduction in any medium, provided the original work is properly cited. 
bial materials including defensins and lysozymes. ${ }^{8}$ Reduced antimicrobial function of defensins was reported in IBD patients with a genetic risk factor allele of the NOD2 gene, ${ }^{9}$ and transcription factor 4 (TCF4), a Wnt transcription factor, is also known to be critical for the proper functioning of Paneth cells and was suggested as another genetic risk factor associated with IBD. ${ }^{10}$ In addition, XBP1 and ATG16L1 converge in Paneth cells as primary factors of IBD, and ER stress exacerbated by XBP1 deficiency might be attenuated by the compensatory mechanism of autophagy activation in Paneth cells. ${ }^{6}$

In the inflammatory loci of IBD patients, there is massive infiltration of inflammatory cells including T cells, neutrophils, monocytes, and macrophages. ${ }^{11,12}$ Recently, the presence of immature myeloid cells, also known as myeloidderived suppressor cells (MDSCs), was also detected in IBD patients as well as in animal models of IBD. ${ }^{13}$ In this review, we will discuss the accumulation and functions of MDSCs in IBD-associated intestinal inflammatory conditions, and a possible association of ER stress on the inflammatory or suppressive functions of MDSC's.

\section{MDSCs IN IMMUNE SYSTEMS}

MDSCs are a heterogeneous cell population consisting of macrophage precursors, dendritic cells, granulocytes, and early myeloid progenitors. ${ }^{14}$ The definition of this cell population is based on its origin, myeloid lineage, and its immunosuppressive function. Since the term "MDSC" does not directly reflect the immaturity of this population, they are also called immature myeloid cells. ${ }^{15}$ They expand during pathological conditions, including infections, inflammations, and cancers in experimental animal models, as well as in human patients. ${ }^{14,16}$ There are two main subsets of MDSCs: polymorphonuclear MDSCs (PMN-MDSCs) and monocytic MDSCs (Mo-MDSCs), especially in murine models of tumor transplantation. ${ }^{17,18}$ In mice, PMN-MDSCs are CD1 1 b $\mathrm{b}^{+} \mathrm{Ly}-$ $6 \mathrm{G}^{+} \mathrm{Ly}-6 \mathrm{C}^{\text {low }}$ cells, while Mo-MDSCs are CD11b Ly-6G Ly$6 \mathrm{C}^{\text {high }}$ cells. ${ }^{19}$ There are some differences in suppressive capacity and functional mechanism between the two subsets ${ }^{20}$ and both PMN-MDSCs and Mo-MDSCs can be found in humans. ${ }^{16,21}$

In the immune system, it is known that the major role of MDSCs is immune suppression, and this seems to be especially true in tumor tissues. ${ }^{15,16}$ The accumulation of MDSCs in tumor-bearing mice and cancer patients is correlated with poor prognoses. MDSCs can inhibit the proliferation and cytokine production of $\mathrm{CD}^{+}$and $\mathrm{CD} 8^{+} \mathrm{T}$ cells through amino acid deprivation and the release of oxidizing molecules. ${ }^{22}$ They also induce regulatory $\mathrm{T}$ cells to suppress immune responses against tumor cells. ${ }^{23}$ Besides, they can modulate the function of $\mathrm{T}$ cells as well as their migration and viability. ${ }^{22}$ In addition to $\mathrm{T}$ cell inhibition, MDSCs suppressed natural killer (NK) cell cytotoxicity and cytokine production, ${ }^{24}$ and suppress the antigen presenting functions of dendritic cells. ${ }^{25}$

Despite their inherent suppressive functions, MDSCs can be converted into immunostimulatory myeloid cells in specific circumstances. ${ }^{26}$ In acute inflammation, such as trauma and sepsis, MDSCs are the sentinel cells for immune-surveillance and act as immune effectors. ${ }^{27}$ Even in the ovarian cancer model, MDSCs in ascites play a role as immunostimulatory antigen presenting cells (APCs) ${ }^{28}$ Furthermore, there is plasticity in the suppressive function of MDSCs. Our recent study also showed that intra-tumoral injection of attenuated Salmonella induced tumor necrosis factor $\alpha$ (TNFa)-producing PMN-MDSCs, which can function as immune effectors. ${ }^{19}$ With the help of NKT cells, MDSCs became immunogenic APCs and stimulated antigen specific T cells. ${ }^{29,30}$ Hence, the divergent roles and the functional plasticity of MDSCs are now interesting subjects in MDSC studies.

\section{MDSCs IN IBD}

IBD is an autoimmune-associated disease characterized by small and large intestinal inflammation. ${ }^{31}$ There are two major forms of IBD, CD and UC. ${ }^{1}$ In the chronic inflammatory condition of IBD, there are complex interactions between several immune cells infiltrating into the intestinal mucosa, with epithelial cells even ignoring the effects of microbiota. ${ }^{11}$ Among them, myeloid cells, including neutrophils, macrophages, and MDSCs, have been a focus of study due to their divergent role in inflammation. ${ }^{32}$ In particular, the immunosuppressive function of MDSCs was suggested in several mouse models of IBD (Table 1). It was reported that $\mathrm{CD} 11 \mathrm{~b}^{+} \mathrm{Gr}-1^{+}$MDSCs were accumulated in a murine colitis model, and they expressed nitric oxide synthase 2 and arginase, which are known to be critical functional mediators of MDSCs. ${ }^{32}$ As well as in a model of IBD, CD14 HLA$\mathrm{DR}^{\text {low }}$ MDSCs with suppressive functions were reported to be increased in the peripheral blood of IBD patients. ${ }^{32}$

Besides MDSCs in IBD models being initially reported as immunosuppressive, as shown in tumor-bearing hosts, the roles of MDSCs during intestinal inflammation have become controversial since recent studies suggested that they functioned as pro-inflammatory myeloid cells. Colonic Mac- $1^{+} \mathrm{Ly}_{6 \mathrm{C}^{\text {int }}} \mathrm{Gr}-\mathrm{1}^{+}$cells, similar to PMN-MDSCs, acquired 
Table 1. Pros and Cons of Myeloid-Derived Suppressor Cells (MDSCs) in IBS

\begin{tabular}{|c|c|c|c|}
\hline Function of MDSC & Model & Role & Reference \\
\hline \multirow[t]{3}{*}{ Immunosuppression } & $2,4,6$-TNBS-induced murine colitis & $\begin{array}{l}\text { Adoptive transfer of CD } 11 \mathrm{~b}^{+} \mathrm{Gr}-1^{+} \text {MDSCs decreased intestinal } \\
\text { inflammation, levels of IFN- } \gamma_{1} \text { IL-17, and TNF- } \alpha\end{array}$ & 39 \\
\hline & $\begin{array}{l}\mathrm{CD}^{+}{ }^{+} \mathrm{CD} 45 \mathrm{RB} \mathrm{B}^{\text {high }} \mathrm{T} \text { cell transfer-induced } \\
\text { chronic colitis in } \mathrm{RAG}-1^{-1-} \text { mice }\end{array}$ & $\begin{array}{l}\text { Ly6C } \mathrm{C}^{\text {high }} \text { monocyte-derived cells restrained Th1 cell responses } \\
\text { and promote generation of Foxp3 }{ }^{+} \text {Tregs and Th17 cells }\end{array}$ & 38 \\
\hline & $\begin{array}{l}\text { Spontaneous developed chronic colitis in } \\
\mathrm{IL}-10^{-1-} \text { mice }\end{array}$ & $\begin{array}{l}\text { Resveratrol-induced } \mathrm{CD} 11 \mathrm{~b}^{+} \mathrm{Gr}-1^{+} \text {cells attenuated T cell } \\
\text { proliferation, and reduced IFN- } \gamma \text { and GM-CSF production } \\
\text { by lamina propria derived T cells in vitro }\end{array}$ & 65 \\
\hline \multirow[t]{2}{*}{ Pro-inflammation } & DSS-induced murine colitis & $\begin{array}{l}\mathrm{CD} 11 \mathrm{~b}^{+} \mathrm{CD} 14^{+} \mathrm{CX} 3 \mathrm{CR} 1^{+} \text {lamina propria } \mathrm{DCs} \text { were derived } \\
\text { from transferred Ly } 6 \mathrm{C}^{\text {high }} \text { monocytes contributed to } \\
\text { severe intestinal inflammation in TNF- } \alpha \text {-dependent manner }\end{array}$ & 12 \\
\hline & $\begin{array}{l}\mathrm{CD}^{+} \mathrm{CD} 45 \mathrm{RB} \mathrm{B}^{\text {high }} \mathrm{T} \text { cell transfer-induced } \\
\text { chronic colitis in } \mathrm{RAG}-2^{-1-} \text { mice }\end{array}$ & $\begin{array}{l}\text { Ly6C }^{\text {high }} \text { monocytes differentiated into } \mathrm{CD} 103^{-} \mathrm{CX} 3 \mathrm{CR} 1^{\text {int }} \mathrm{CD} 11 \mathrm{~b}^{+} \\
\mathrm{DC} \text {, and produced high levels of pro-inflammatory cytokines, } \\
\text { including IL-12, IL-23, iNOS, and TNF, in the colon }\end{array}$ & 34 \\
\hline
\end{tabular}

TNBS, trinitrobenzene sulfonic acid; IFN- $\gamma$, interferon $\gamma_{i}$ IL-17, interleukin 17; TNF- $\alpha$, tumor necrosis factor $\alpha$; DSS, dextran sulfate sodium; GMCSF, granulocyte-macrophage colony-stimulating factor; DCs, dendritic cells; RAG-1, recombination activation gene-1; iNOS, inducible nitric oxide synthase.

stimulatory APC functions and induced T cell activation and pro-inflammatory cytokine production. ${ }^{33}$ In addition, adoptive transferred Ly6 $\mathrm{C}^{\text {hi }}$ monocytes were converted into pro-inflammatory cells. They then contributed to intestinal inflammation, ${ }^{12}$ and produced pro-inflammatory cytokines in a murine model of IBD. ${ }^{34}$

These controversial roles of MDSCs in IBD might be partially due to interleukin 17 (IL-17) cytokine production, which could be at least partially ascribed to increased differentiation of Th17 cells. Th17 cells are known to act as pathogenic effector cells in various immune-related diseases, including experimental autoimmune encephalomyelitis, arthritis, and IBD. ${ }^{13}$ In the case of IL-17, one study showed that this cytokine had a pathogenic role in severe intestinal inflammation ${ }^{35}$ but another study demonstrated IL-17-mediated protection in murine colitis. ${ }^{36}$

Interestingly, it was recently reported that $\mathrm{CD} 11 \mathrm{~b}^{+} \mathrm{Gr}-1^{+}$ MDSCs enhanced Th17 cell differentiation and contributed to the pathogenesis of experimental autoimmune encephalomyelitis. ${ }^{37}$ Likewise, a recent study showed that immunosuppressive MDSCs inhibited Th1 responses while they enhanced Th17 generation. ${ }^{38}$ In a chronic colitis model, proinflammatory colonic Mac- $1^{+} \mathrm{Ly} 6 \mathrm{C}^{\text {int }} \mathrm{Gr}-1^{+}$cells induced IL-
17 production by T cells. ${ }^{33}$ Collectively, this series of studies suggest that MDSCs induced by intestinal inflammation conditions might be involved in Th17 generation and IL-17 production. As described, Th17 cells can contribute to establishing the pro-inflammatory environment and pathogenesis of IBD. On the contrary, MDSCs were initially reported to inhibit the production of several pro-inflammatory cytokines including IL-17, and functioned as immune regulators in several other inflammatory conditions including cancer and chronic infections. ${ }^{39}$ Thus, the role of MDSCs in IBD is still controversial, and might be closely associated with the production of IL-17 or the induction of IL-17-producing T cells.

\section{ER STRESS AND IBD}

ER is a type of organelle in eukaryotic cells responsible for the folding, modification, maturation, and trafficking of newly synthesized proteins, and only properly folded proteins are transported from the rough ER to the Golgi apparatus for secretion. ${ }^{40}$ Thus, the precise regulation of ER function is critical for the maintenance of cellular homeostasis. ${ }^{41}$ The condition in which unfolded or misfolded proteins accumulated in the ER is known as ER stress, and can be caused by 
several factors including disturbances in redox regulation, calcium regulation, glucose deprivation, and viral infection. ${ }^{42}$ Experimentally, several conditions including $\mathrm{ER} \mathrm{Ca}^{2+}$ depletion, defective glycosylation, viral infection, and inflammatory conditions are also known to induce ER stress. ${ }^{43}$

ER stress activates multiple cellular processes known as unfolded protein responses (UPRs), and three branches of UPRs have been discussed extensively in previous reviews. ${ }^{42,44}$ Under ER stress conditions, misfolded or unfolded protein are accumulated in the ER lumen, and trigger UPRs to restore normal ER function. UPR signaling results in the adaptation of cells to ER stress by increasing activation of ER chaperon function, ER trafficking, degradation of ERresident protein, as well as by inhibiting CAP-dependent translation through phosphorylation of the $\alpha$-subunit of eukaryotic initiation factor $2(\mathrm{eIF} 2 \alpha){ }^{45}$ Otherwise, excessive ER stress induces apoptosis via C/EBP-homologous protein (CHOP) and the inositol-requiring transmembrane kinase/ endonuclease $1 \alpha(\operatorname{IRE} 1 \alpha) /$ TNF receptor-associated factor 2 (TRAF2)/TNF- $\alpha$ pathway. ${ }^{46}$ In addition, sustained ER stress also induces cell death due to failure in UPR signaling to induce the homeostatic adaptation of cells. ${ }^{47}$

In mammalian cells, ER stress evokes UPR to resolve constraint inside the ER. ${ }^{44}$ UPRs consist of three highly conserved pathways including PKR-like eukaryotic initiation factor $2 \alpha$ kinase (PERK), IRE1, and activating transcription factor-6 (ATF6). Among them, the IRE1 $\alpha$ pathway includes splicing of a gene encoding XBP1. ${ }^{4}$ Spliced XBP1 (sXBP1) is critical for the functions of the ER such as expansion and secretion, especially in several highly secretory cells including plasma cells and pancreatic and salivary gland epithelial cells. ${ }^{48,49}$ The function of the unspliced form of XBP1 (uXPB1) is not well known, and uXBP1 is highly unstable. Instead, SXPB1 triggers the transcription of genes for the quality control and maintenance of ER functions. IRE1 is an ancestrally conserved pathway of UPR, and also possesses kinase activity to phosphorylate TRAF2 as well as endonuclease activity. ${ }^{4}$ Accordingly, intestinal epithelial cell-specific depletion of XBP1 is known to initiate spontaneous small intestinal inflammation in mice.

UPR is known to intersect with several inflammatory pathways including $\mathrm{I}_{\kappa} \mathrm{B}$ kinase (IKK) and c-Jun N-terminal kinases (JNK), ${ }^{50,51}$ and is also associated with inflammation in obese and diabetic patients. ${ }^{52}$ In addition, ER stress has been associated with the development of IBD. ${ }^{4}$ In humans, several genes associated with ER stress including XBP1, anterior gradient 2 (AGR2), mucin 19 (MUC19), and ORMDL sphingolipid biosynthesis regulator 3 (ORMDL3) have been reported as genetic risk factors for IBD, and increased ER stress has been observed in patients with IBD. ${ }^{5}$ In several mouse models, ER stress induced by deletion of some ER chaperones such as ATF6 or p58 ${ }^{\mathrm{IPK}}$ led to the development of severe intestinal inflammation after dextran sulfate sodium (DSS) administration, ${ }^{53}$ and the administration of chemical chaperones including 4-phenylbutyrate and tauroursodeoxycholate ameliorated colitis in those mice. ${ }^{53}$ In addition, conditional knockout of XBP1 in intestinal epithelial cells causes small intestinal enteritis with crypt abscesses reminiscent of human IBD, ${ }^{4}$ and AGR2 knockout mice develop granulomatous ileocolitis. ${ }^{54}$ Interestingly, UPR signaling was found to be impaired in colonic epithelial cells of protein kinase RNA-activated $(\mathrm{PKR})^{--}$mice with a reduced level of phosphorylated eIF2 $\alpha$ and diminished ER chaperons, resulting in more severe DSS-induced colitis in these mice. ${ }^{55} \mathrm{In}$ addition, glutamine treatment attenuates ER stress increased in a trinitrobenzene sulfonate (TNBS)-treated colitis model through modulation of UPR signaling, and diminishes the severity of macroscopic damage and apoptotic cell death. ${ }^{56}$

\section{ER STRESS AND THE DIVERGENT FUNCTIONS OF MDSCs}

In tumor-bearing hosts, it has been reported that ER stress is transmitted from tumor cells to myeloid cells. ${ }^{57}$ In association with increased inflammation by ER stress, ER stressconditioned medium obtained from tumor cells culture with ER stress inducers resulted in up-regulation of ER stress in myeloid cells. Similarly, infectious ER stress has also been reported in tumor cells, which was known to be mediated by Par- 4 secreted by ER stressed cells. ${ }^{58}$ Hypoxic tumor microenvironments could induce an ER stress condition, as well as increased reactive oxygen species generated in MDSCs induced ER stress. Increased ER stress results in early apoptosis of MDSCs in a TNF-related apoptosis-inducing ligandreceptor (TRAIL-R)-dependent manner, which in turn accelerates the generation of MDSCs in bone marrow. Indeed, MDSCs found in tumor-bearing mice and cancer patients showed significantly higher levels of ER stress compared with healthy controls. ${ }^{59}$ However, it is not clear whether ER stress increased in IBD condition influences on intestinal MDSCs found in IBD patients as well as on their immunosuppressive or inflammatory functions.

Although aggravation of inflammation by ER stress seems to be certain in several disease conditions, the mechanism by which ER stress triggers inflammation remains largely unknown. IRE1/TRAF2-mediated JNK activation and the 
nuclear factor- $\kappa \mathrm{B}(\mathrm{NF}-\kappa \mathrm{B})$ pathway could explain the inflammatory responses observed in the ER stress condition. ER stress also activates cleavage of ATF6 to activate the expression of acute-phase protein genes in the liver, and mediates acute inflammatory responses. ${ }^{60}$ Recent studies have also suggested the role of the nucleotide-binding oligomerization domain, leucine rich repeat, and pyrin domain containing 3 (NALP3) inflammasome in chronic inflammatory disease with ER stress. ${ }^{61}$ Unregulated activation of caspase-1 and subsequent overproduction of IL- $1 \beta$ through inflammasome activation might be associated with the perpetuation of IBD. Indeed, there is an increased level of IL-1 $\beta$ in the intestinal specimens of IBD patients. ${ }^{62}$ On the contrary, loss of function in NOD2 or inflammasomes could result in dysbiosis by decreased IL-1 $\beta .^{63}$ Thus, the involvement of several genetic risk factors, including NOD2, ATG16L1, NALP3, and chemokine (C-C motif) receptor 6 in the inflammatory status of MDSCs need to be further elucidated.

\section{CONCLUSIONS}

ER stress responses in MDSCs as well as in intestinal epithelial cells might be critical for the homeostatic regulation of gut immunity. In this review, we focused on the roles of MDSCs on intestinal inflammation, especially in animal models of IBD and also in IBD patients. The recent advances in experimental techniques for intestinal tissues, wide availability of germ-free mice, genome-wide analysis of patients' genetic information, and metagenomic analysis of commensals increase the understanding of the development and progress of IBD, and hence provide some clues for the development of therapeutic drugs for the treatment of IBD. In particular, some strategies to regulate ER stress responses in MDSCs as well as in the intestinal epithelium might be novel ways to prevent or treat intestinal inflammation in IBD patients.

\section{REFERENCES}

1. Baumgart DC, Sandborn WJ. Crohn's disease. Lancet 2012;380:1590-1605.

2. Ogura Y, Bonen DK, Inohara N, et al. A frameshift mutation in NOD2 associated with susceptibility to Crohn's disease. Nature 2001;411:603-606.

3. Henckaerts L, Figueroa C, Vermeire S, Sans M. The role of genetics in inflammatory bowel disease. Curr Drug Targets 2008;9:361-368.
4. Kaser A, Lee AH, Franke A, et al. XBP1 links ER stress to intestinal inflammation and confers genetic risk for human inflammatory bowel disease. Cell 2008;134:743-756.

5. Kaser A, Zeissig S, Blumberg RS. Genes and environment: how will our concepts on the pathophysiology of IBD develop in the future? Dig Dis 2010;28:395-405.

6. Adolph TE, Tomczak MF, Niederreiter L, et al. Paneth cells as a site of origin for intestinal inflammation. Nature 2013;503:272276.

7. Koslowski MJ, Teltschik Z, Beisner J, et al. Association of a functional variant in the Wnt co-receptor LRP6 with early onset ileal Crohn's disease. PLoS Genet doi: 10.1371/journal. pgen.1002523. Published online 23 Feburary 2012.

8. Farin HF, Karthaus WR, Kujala P, et al. Paneth cell extrusion and release of antimicrobial products is directly controlled by immune cell-derived IFN-gamma. J Exp Med 2014;211:1393-1405.

9. Wehkamp J, Harder J, Weichenthal M, et al. NOD2 (CARD15) mutations in Crohn's disease are associated with diminished mucosal alpha-defensin expression. Gut 2004;53:1658-1664.

10. Koslowski MJ, Kubler I, Chamaillard M, et al. Genetic variants of Wnt transcription factor $T C F-4$ (TCF7L2) putative promoter region are associated with small intestinal Crohn's disease. PLoS One doi: 10.1371/journal.pone.0004496. Published online 16 Feburary 2009.

11. Fournier BM, Parkos CA. The role of neutrophils during intestinal inflammation. Mucosal Immunol 2012;5:354-366.

12. Varol C, Vallon-Eberhard A, Elinav E, et al. Intestinal lamina propria dendritic cell subsets have different origin and functions. Immunity 2009;31:502-512.

13. Ostanin DV, Bhattacharya D. Myeloid-derived suppressor cells in the inflammatory bowel diseases. Inflamm Bowel Dis 2013;19:2468-2477.

14. Gabrilovich DI, Bronte V, Chen SH, et al. The terminology issue for myeloid-derived suppressor cells. Cancer Res 2007;67:425; author reply 426.

15. Talmadge JE, Gabrilovich DI. History of myeloid-derived suppressor cells. Nat Rev Cancer 2013;13:739-752.

16. Gabrilovich DI, Nagaraj S. Myeloid-derived suppressor cells as regulators of the immune system. Nat Rev Immunol 2009;9:162174.

17. Youn JI, Nagaraj S, Collazo M, Gabrilovich DI. Subsets of myeloid-derived suppressor cells in tumor-bearing mice. J Immunol 2008;181:5791-5802.

18. Kim YS, Kim YJ, Lee JM, et al. Functional changes in myeloidderived suppressor cells (MDSCs) during tumor growth: FKBP51 contributes to the regulation of the immunosuppressive function of MDSCs. J Immunol 2012;188:4226-4234. 
19. Hong EH, Chang SY, Lee BR, et al. Intratumoral injection of attenuated Salmonella vaccine can induce tumor microenvironmental shift from immune suppressive to immunogenic. Vaccine 2013;31:1377-1384.

20. Youn JI, Gabrilovich DI. The biology of myeloid-derived suppressor cells: the blessing and the curse of morphological and functional heterogeneity. Eur J Immunol 2010;40:2969-2975.

21. Ko JS, Zea AH, Rini BI, et al. Sunitinib mediates reversal of myeloid-derived suppressor cell accumulation in renal cell carcinoma patients. Clin Cancer Res 2009;15:2148-2157.

22. Gabrilovich DI, Ostrand-Rosenberg S, Bronte V. Coordinated regulation of myeloid cells by tumours. Nat Rev Immunol 2012;12:253-268.

23. Serafini P, Mgebroff S, Noonan K, Borrello I. Myeloid-derived suppressor cells promote cross-tolerance in B-cell lymphoma by expanding regulatory T cells. Cancer Res 2008;68:5439-5449.

24. Hoechst B, Voigtlaender T, Ormandy L, et al. Myeloid derived suppressor cells inhibit natural killer cells in patients with hepatocellular carcinoma via the NKp30 receptor. Hepatology 2009;50:799-807.

25. Hu CE, Gan J, Zhang RD, Cheng YR, Huang GJ. Up-regulated myeloid-derived suppressor cell contributes to hepatocellular carcinoma development by impairing dendritic cell function. Scand J Gastroenterol 2011;46:156-164.

26. Chang SY, Kim YJ, Ko HJ. Potential therapeutic anti-tumor effect of a Salmonella-based vaccine. Hum Vaccin Immunother 2013;9:1654-1660.

27. Cuenca AG, Delano MJ, Kelly-Scumpia KM, et al. A paradoxical role for myeloid-derived suppressor cells in sepsis and trauma. Mol Med 2011;17:281-292.

28. Tomihara K, Guo M, Shin T, et al. Antigen-specific immunity and cross-priming by epithelial ovarian carcinoma-induced $\mathrm{CD}_{1} 1 \mathrm{~b}^{+} \mathrm{Gr}-1^{+}$cells. J Immunol 2010;184:6151-6160.

29. Ko HJ, Lee JM, Kim YJ, Kim YS, Lee KA, Kang CY. Immunosuppressive myeloid-derived suppressor cells can be converted into immunogenic APCs with the help of activated NKT cells: an alternative cell-based antitumor vaccine. J Immunol 2009;182:1818-1828.

30. Lee JM, Seo JH, Kim YJ, Kim YS, Ko HJ, Kang CY. The restoration of myeloid-derived suppressor cells as functional antigenpresenting cells by NKT cell help and all-trans-retinoic acid treatment. Int J Cancer 2012;131:741-751.

31. Fakhoury M, Negrulj R, Mooranian A, Al-Salami H. Inflammatory bowel disease: clinical aspects and treatments. J Inflamm Res 2014;7:113-120.

32. Haile LA, von Wasielewski R, Gamrekelashvili J, et al. Myeloidderived suppressor cells in inflammatory bowel disease: a new immunoregulatory pathway. Gastroenterology 2008;135:871881.
33. Ostanin DV, Kurmaeva E, Furr K, et al. Acquisition of antigenpresenting functions by neutrophils isolated from mice with chronic colitis. J Immunol 2012;188:1491-1502.

34. Rivollier A, He J, Kole A, Valatas V, Kelsall BL. Inflammation switches the differentiation program of Ly6 $\mathrm{C}^{\text {hi }}$ monocytes from antiinflammatory macrophages to inflammatory dendritic cells in the colon. J Exp Med 2012;209:139-155.

35. Leppkes M, Becker C, Ivanov II, et al. ROR $\gamma$-expressing Th17 cells induce murine chronic intestinal inflammation via redundant effects of IL-17A and IL-17F. Gastroenterology 2009;136:257-267.

36. O'Connor W, Jr., Kamanaka M, Booth CJ, et al. A protective function for interleukin $17 \mathrm{~A}$ in $\mathrm{T}$ cell-mediated intestinal inflammation. Nat Immunol 2009;10:603-609.

37. Yi H, Guo C, Yu X, Zuo D, Wang XY. Mouse CD11b ${ }^{+}$Gr- $1^{+}$ myeloid cells can promote Th17 cell differentiation and experimental autoimmune encephalomyelitis. J Immunol 2012;189:4295-4304.

38. Kurmaeva E, Bhattacharya D, Goodman W, et al. Immunosuppressive monocytes: possible homeostatic mechanism to restrain chronic intestinal inflammation. J Leukoc Biol 2014;96:377-389.

39. Guan Q, Moreno S, Qing G, et al. The role and potential therapeutic application of myeloid-derived suppressor cells in TNBS-induced colitis. J Leukoc Biol 2013;94:803-811.

40. McGuckin MA, Eri RD, Das I, Lourie R, Florin TH. ER stress and the unfolded protein response in intestinal inflammation. Am J Physiol Gastrointest Liver Physiol 2010;298:G820-G832.

41. Mandl J, Meszaros T, Banhegyi G, Csala M. Minireview: endoplasmic reticulum stress: control in protein, lipid, and signal homeostasis. Mol Endocrinol 2013;27:384-393.

42. Kaufman RJ. Stress signaling from the lumen of the endoplasmic reticulum: coordination of gene transcriptional and translational controls. Genes Dev 1999;13:1211-1233.

43. Jheng JR, Ho JY, Horng JT. ER stress, autophagy, and RNA viruses. Front Microbiol 2014;5:388.

44. Todd DJ, Lee AH, Glimcher LH. The endoplasmic reticulum stress response in immunity and autoimmunity. Nat Rev Immunol 2008;8:663-674.

45. Baird TD, Wek RC. Eukaryotic initiation factor 2 phosphorylation and translational control in metabolism. Adv Nutr 2012;3:307-321.

46. Garg AD, Kaczmarek A, Krysko O, Vandenabeele P, Krysko DV, Agostinis P. ER stress-induced inflammation: does it aid or impede disease progression? Trends Mol Med 2012;18:589-598.

47. Kim I, Xu W, Reed JC. Cell death and endoplasmic reticulum stress: disease relevance and therapeutic opportunities. Nat Rev Drug Discov 2008;7:1013-1030. 
48. Todd DJ, McHeyzer-Williams LJ, Kowal C, et al. XBP1 governs late events in plasma cell differentiation and is not required for antigen-specific memory B cell development. J Exp Med 2009;206:2151-2159.

49. Lee AH, Chu GC, Iwakoshi NN, Glimcher LH. XBP-1 is required for biogenesis of cellular secretory machinery of exocrine glands. EMBO J 2005;24:4368-4380.

50. Deng J, Lu PD, Zhang Y, et al. Translational repression mediates activation of nuclear factor kappa B by phosphorylated translation initiation factor 2. Mol Cell Biol 2004;24:10161-10168.

51. Hu P, Han Z, Couvillon AD, Kaufman RJ, Exton JH. Autocrine tumor necrosis factor alpha links endoplasmic reticulum stress to the membrane death receptor pathway through IRE $1 \alpha$-mediated NF- $\kappa$ B activation and down-regulation of TRAF2 expression. Mol Cell Biol 2006;26:3071-3084.

52. Hotamisligil GS. Endoplasmic reticulum stress and the inflammatory basis of metabolic disease. Cell 2010;140:900-917.

53. Cao SS, Zimmermann EM, Chuang BM, et al. The unfolded protein response and chemical chaperones reduce protein misfolding and colitis in mice. Gastroenterology 2013;144:9891000.

54. Park SW, Zhen G, Verhaeghe C, et al. The protein disulfide isomerase AGR2 is essential for production of intestinal mucus. Proc Natl Acad Sci U S A 2009;106:6950-6955.

55. Cao SS, Song B, Kaufman RJ. PKR protects colonic epithelium against colitis through the unfolded protein response and prosurvival signaling. Inflamm Bowel Dis 2012;18:1735-1742.

56. Crespo I, San-Miguel B, Prause C, et al. Glutamine treatment attenuates endoplasmic reticulum stress and apoptosis in TNBSinduced colitis. PLoS One doi: 10.1371/journal.pone.0050407. Published online 28 November 2012.
57. Mahadevan NR, Rodvold J, Sepulveda H, Rossi S, Drew AF, Zanetti M. Transmission of endoplasmic reticulum stress and pro-inflammation from tumor cells to myeloid cells. Proc Natl Acad Sci U S A 2011;108:6561-6566.

58. Burikhanov R, Zhao Y, Goswami A, Qiu S, Schwarze SR, Rangnekar VM. The tumor suppressor Par-4 activates an extrinsic pathway for apoptosis. Cell 2009;138:377-388.

59. Condamine T, Kumar V, Ramachandran IR, et al. ER stress regulates myeloid-derived suppressor cell fate through TRAIL-Rmediated apoptosis. J Clin Invest 2014;124:2626-2639.

60. Zhang K, Shen X, Wu J, et al. Endoplasmic reticulum stress activates cleavage of CREBH to induce a systemic inflammatory response. Cell 2006;124:587-599.

61. Menu P, Mayor A, Zhou R, et al. ER stress activates the NLRP3 inflammasome via an UPR-independent pathway. Cell Death Dis 2012;3:e261.

62. Casini-Raggi V, Kam L, Chong YJ, Fiocchi C, Pizarro TT, Cominelli F. Mucosal imbalance of IL-1 and IL-1 receptor antagonist in inflammatory bowel disease. A novel mechanism of chronic intestinal inflammation. J Immunol 1995;154:2434-2440.

63. Villani AC, Lemire M, Fortin G, et al. Common variants in the NLRP3 region contribute to Crohn's disease susceptibility. Nat Genet 2009;41:71-76.

64. Zhang R, Ito S, Nishio N, Cheng Z, Suzuki H, Isobe K. Up-regulation of Gr1+CD11b+ population in spleen of dextran sulfate sodium administered mice works to repair colitis. Inflamm Allergy Drug Targets 2011;10:39-46.

65. Singh UP, Singh NP, Singh B, et al. Role of resveratrol-induced $\mathrm{CD}_{1} \mathrm{~b}^{+} \mathrm{Gr}-\mathrm{l}^{+}$myeloid derived suppressor cells (MDSCs) in the reduction of $\mathrm{CXCR}^{+} \mathrm{T}$ cells and amelioration of chronic colitis in IL-10/- mice. Brain Behav Immun 2012;26:72-82. 